\title{
0 exercício físico crónico altera o perfil leucocitário e a taxa de fagocitose de ratos estressados
}

\author{
Elizabeth Nascimento ${ }^{1}$, Taisy Cavalcante ${ }^{1}$ \\ Silene Pereira ${ }^{1}$, América Palmeira ${ }^{1}$ \\ M. Carolina Rocha ${ }^{1}$, Marcelo T. Viana ${ }^{1}$ \\ Raul Manhães-de-Castro ${ }^{1}$ \\ Célia MMB de-Castro², José Duarte ${ }^{3}$ \\ Carol G. Leandro ${ }^{1,3}$
}

https://doi.org/10.5628/rpcd.04.03.26

\section{RESUMO}

O exercício físico moderado parece ser benéfico ao sistema imunológico, ao contrário do stress. O presente estudo pretendeu verificar se o exercício físico crónico prévio a um estado de stress agudo altera a contagem de leucócitos do sangue e a função fagocítica de macrófagos alveolares. Ratos machos Wistar $(\mathrm{n}=61)$ foram divididos em não-exercitados (NE), não-exercitados + stress $(\mathrm{NE}+\mathrm{S})$, exercitados $(\mathrm{E})$, e exercitados + stress (E $+S)$. Os animais exercitados foram submetidos a natação durante 6 semanas ( $45 \mathrm{~min} / \mathrm{dia}, 5$ dias/semana e sobrecarga de até $3 \%$ do peso corporal). Os grupos $\mathrm{NE}+\mathrm{S}$ e $\mathrm{E}+\mathrm{S}$ foram submetidos ao stress agudo de contenção (40 min) 24 horas a seguir à última sessão de treino. A contagem de hemácias, hemoglobina e hematócrito não foi alterada nos grupos estudados. Os animais NE $+\mathrm{S}$ apresentaram uma diminuição na contagem total de leucócitos e de linfócitos e um aumento de neutrófilos no sangue. Estas alterações não foram verificadas nos animais exercitados. A taxa de fagocitose de macrófagos aumentou no grupo E e não apresentou diminuição no grupo $\mathrm{E}$ $+\mathrm{S}$. Nossos resultados sugerem que o exercício físico moderado durante 6 semanas atenua os efeitos do stress agudo no perfil leucocitário e melhora a função de macrófagos. Estudos são necessários para avaliar a significância clínica e os mecanismos subjacentes a tais alterações.

Palavras-chave: exercício físico moderado, stress, sistema imunológico.

\author{
${ }^{1}$ Laboratório de Fisiologia da Nutrição, Departamento \\ de Nutrição, Centro de Ciências da Saúde (CCS) \\ Universidade Federal de Pernambuco, Brasil \\ ${ }^{2}$ Laboratório de Imunopatologia Keizo Asami \\ Departamento de Medicina Tropical, CCS, UFPE, Brasil \\ ${ }^{3}$ Laboratório de Bioquímica e Morfologia Experimental \\ Faculdade de Ciências do Desporto e de Educação Física \\ Universidade do Porto, Portugal
}

\section{ABSTRACT \\ Chronic physical activity modifies blood leukocyte profile and phagocytosis rate of stressed rats}

Moderate physical exercise may be beneficial for immune system, unlike a stress state. The present study intended to verify if a chronic physical exercise performed before a stress state can change the blood leukocyte profile and the phagocytic function of alveolar macrophages. Male Wistar rats $(n=61)$ were assigned to 4 groups: non-exercised (NE), non-exercised plus stress $(N E+S)$, exercised $(E)$ and exercised plus stress $(E+S)$. The exercised groups $(E$ and $E+S)$ were submitted to swimming exercise during six weeks (45 min/day, 5 days p/week and overload until 3\% of body weight). The stress groups (NE+S and $E+S)$ were submitted to an acute restrain stress (40 min) 24 hours after the last bout of exercise. The blood red series were not altered in all studied groups. However, when compared to NE group, the nonexercised animals submitted to stress showed a decrease in the total number of leukocytes with a reduced number of lymphocytes and an increase in neutrophil count. These alterations were not observed in exercised animals $(E+S)$. The phagocytic ratio of macrophages increased in $E$ group and did not show any decrease in $E+S$ group. Our results suggest that physical exercise performed during six weeks attenuates the stress-induced alterations in the leukocyte profile and enhances the phagocytic function of macrophages. More studies are necessary to evaluate the clinical significance and the mechanism of such alterations.

Key Words: moderate physical exercise, stress, immune system. 


\section{INTRODUÇÃO}

O stress, tal como uma carga súbita de exercício físico (EF) muito intenso, a exposição a temperaturas extremas, um trauma ou infecção, parece suprimir o sistema imunológico (SI) (3). O SI é altamente complexo e composto de numerosos tipos celulares e mediadores solúveis (14). Sob a influência da regulação neuroendócrina e de outros factores, o SI é visto de forma integrada respondendo diferentemente a cada tipo de estímulo (3). A variabilidade dos tipos celulares (macrófagos, linfócitos, células natural killer (NK) e granulócitos) e suas funções respondem de forma diferenciada aos diversos estímulos. Particularmente os macrófagos parecem ser sensíveis aos efeitos do stress via receptores para glucocorticóides (29). Os glucocorticóides parecem mediar muitos efeitos imunossupressores induzidos pelo stress (3). Estas hormonas, em grande concentração, inibem a migração de células inflamatórias para locais lesionados, a proliferação de linfócitos, a actividade das células NK, a capacidade fagocítica dos macrófagos e a produção de anião superóxido por macrófagos $(4,9,30)$. Elevadas concentrações de cortisol estimulam a apoptose de timócitos e podem causar linfocitopenia, monocitopenia e neutrofilia (3). Além disso, parecem induzir baixas na regulação e na densidade de receptores de linfócitos $\mathrm{T}$ e aumentar a taxa de catabolismo, reduzindo as reservas de aminoácidos que são necessários para proliferação de linfócitos B e síntese de imunoglobulinas (25).

As alterações no SI associadas ao exercício físico, enquanto modelo mensurável de indução de stress físico, têm sido relatadas $(4,5,23,24)$. As evidências disponíveis demonstram o papel modulador do exercício físico agudo (carga súbita de EF) sobre a dinâmica e a funcionalidade das componentes do SI (para revisão ver 16).

Durante e imediatamente a seguir a uma carga de $\mathrm{EF}$, ocorre a libertação de mediadores inflamatórios, activação de leucócitos e do sistema complemento, libertação de citocinas, além da síntese e libertação das proteínas de fase aguda dos hepatócitos $(3,4,21)$. Há também um aumento na concentração e na função das células NK, linfócitos T e B, e na actividade fagocítica de monócitos/macrófagos $(21,30)$. Estas alterações parecem estar intimamente relacionadas ao aumento no metabolismo, à produção de calor, e aos ajustamentos hormonais e fisiológicos durante o EF (21). Contudo, a magnitude e o direccionamento da resposta imune são transitórios e directamente influenciados pela intensidade, duração, frequência e tipo do esforço (12).

Se o EF é realizado rotineiramente (exercício crónico) e com intensidade leve ou moderada, o organismo se adapta (efeito do treinamento) e o stress imposto parece ser minimizado ou reduzido (29). Estudos recentes vêm relatando o efeito benéfico do exercício físico regular sobre as componentes do SI $(2,4,14)$. Em resposta a este tipo de esforço, há uma melhora de muitas funções imunes, podendo retardar ou até mesmo prevenir a incidência, a progressão ou o alastramento de tumores (2). Neste sentido, estudos vêm demonstrando um aumento na actividade antitumoral e citotóxica de macrófagos e linfócitos, antimicrobicida e fagocítica de neutrófilos, e citotóxica de células NK $(10,21,23,28)$.

Uma vez delineados os efeitos do stress e do EF regular sobre a dinâmica e algumas funções de células imunes, o presente estudo teve como objectivo verificar se os animais que foram exercitados previamente, quando submetidos a uma situação de stress, apresentam o mesmo perfil leucocitário de animais somente estressados. Em adição, pretendemos verificar o efeito modulador do EF regular sobre a taxa de fagocitose de macrófagos de ratos estressados.

\section{MATERIAL E MÉTODOS \\ Amostra}

Ratos albinos machos da linhagem Wistar com 60 dias de idade $(209-221 \mathrm{~g})$ foram divididos em dois grupos não-exercitados - NE $(n=31)$ e exercitados $E(n=30)$. Os animais foram mantidos em gaiolas colectivas com temperatura ambiente próxima de $22^{\circ} \mathrm{C}$ e receberam dieta e água ad libitum. Manteve-se um ciclo claro/escuro de 12/12 horas (claro das $6 \mathrm{~h}$ às $18 \mathrm{~h}$; escuro das $18 \mathrm{~h}$ às $6 \mathrm{~h}$ ). Em cinco gaiolas, um dos animais permaneceu isento de qualquer tipo de intervenção e manipulação de forma a manter o controle do experimento (dado normativo [DN], $\mathrm{n}=5$ ). $\mathrm{O}$ peso corporal dos animais foi monitorado semanalmente durante o período do experimento. Este estudo foi aprovado pelo Colégio Brasileiro de Experimentação com Animais de Laboratório (COBEA). 


\section{Protocolo de Exercício Físico}

O protocolo de exercício físico foi realizado no período da manhã (entre as $10 \mathrm{~h}$ e as $12 \mathrm{~h}$ ). Os animais foram submetidos à natação durante 6 semanas, 45 $\mathrm{min} / \mathrm{dia}, 5$ dias/semana e sobrecarga de até $3 \%$ do peso corporal presa à cauda do animal. $\mathrm{O}$ tanque de natação continha um sistema de aquecimento mantendo a temperatura da água entre $30^{\circ} \mathrm{e} 32^{\circ} \mathrm{C}$. Aos 60 dias de vida, os animais iniciaram o período de adaptação ao exercício $\left(1^{\circ} \mathrm{dia}=10 \mathrm{~min}, 2^{\circ} \mathrm{dia}=20 \mathrm{~min} ; 3^{\circ}\right.$ $\mathrm{dia}=30 \mathrm{~min} ; 4^{\circ} \mathrm{dia}=40 \mathrm{~min}$ e $5^{\circ} \mathrm{dia}=45 \mathrm{~min}$ ). A seguir, os ratos foram exercitados com incremento de sobrecarga ( $2^{\text {a }}$ semana $=1 \%$; $3^{\text {a }}$ semana $=2 \%$; $4^{a}$ semana $=2 \%$; $5^{a}$ semana $=3 \%$ e $6^{a}$ semana $=3 \%$ ). O grupo não-exercitado permaneceu em uma cuba com água (10 $\mathrm{cm}$ de profundidade) por $45 \mathrm{~min}$, sem realização do esforço físico para controle do stress da água. A seguir aos procedimentos os animais foram cuidadosamente secados e permaneceram em ambiente aquecido para evitar o stress provocado pelo frio e problemas adicionais de saúde.

\section{Indução de stress}

A seguir à última sessão de exercício físico (24 horas), metade dos animais de cada grupo foi submetida ao stress de contenção. Assim, os animais nãoexercitados foram divididos em NE $(n=15)$ e NE e estressados $-N E+S(n=16)$. E os animais exercitados foram divididos em exercitados - E $(n=15)$ e exercitados e estressados $-E+S(n=15)$. Para obtenção de stress agudo utilizámos o protocolo descrito por De Castro et al. (7). Em resumo: os animais foram mantidos em cilindros de plástico PVC $(24 \mathrm{~cm}$ de comprimento $x 8 \mathrm{~cm}$ de diâmetro), onde permaneceram imobilizados durante 40 minutos.

\section{Parâmetros analisados}

Hemograma: Foram retirados $0,5 \mathrm{ml}$ de sangue (com EDTA a 3\%) da cauda do animal anestesiado. Para determinação da hemoglobina foi utilizado o método descrito por Hainline (11) de cianometemoglobina (10 $\mu \mathrm{L}$ de sangue diluído em $5 \mathrm{~mL}$ de solução hipotônica). Em resumo: extrusão da hemoglobina através da lise dos eritrócitos e formação do produto colorido cianometemoglobina, a partir da reacção da hemoglobina com cianetos. A concentração foi inferida por espectrofotometria (Beckman DU-62) com filtro de $540 \mathrm{~nm}$, expressa em $\mathrm{mg} / \mathrm{dl}$ através da fórmula: $\mathrm{Hb}=\mathrm{DO}$ da amostra $\mathrm{xC}$, onde: $\mathrm{Hb}=$ concentração de hemoglobina, $\mathrm{DO}=$ densidade óptica e $\mathrm{FC}=$ factor de conversão. Os valores de hematócrito foram determinados em percentagem pela técnica de micro-hematócrito em leitor de microcapilar por centrifugação (International Microcapillary Reader IEC). Para a contagem de hemácias por $1 \mathrm{~mm}^{3} \mathrm{de}$ sangue foi utilizada solução tampão fosfato de sódio (PBS) a $0,1 \mathrm{M}$ com $\mathrm{pH}=7.4$ na proporção de 1:200 em hemocitômetro (27). Para o cálculo foi utilizada a fórmula: $\mathrm{Hm} \times 5 \times 200 \times 10$, onde: $\mathrm{Hm}=$ número

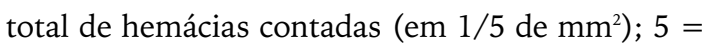
factor de conversão para $1 \mathrm{~mm}^{2} ; 200=$ factor de conversão da diluição utilizada; 10 = factor de conversão para $1 \mathrm{~mm}^{3}$ (profundidade da lâmina). O resultado foi obtido em número de células/ml de sangue. Para contagem total de leucócitos, retirámos amostras de sangue pré e pós o procedimento do stress em todos os grupos. As amostras de sangue foram diluídas (1:200) em solução de TURK (ácido acético a 3\%) (Stibbe et al., 1985). Os leucócitos foram contados em hemocitômetro com auxílio do microscópio óptico. O resultado foi obtido com a fórmula: Leucócitos $\times \mathrm{mm}^{3}$ de sangue $=($ Lc. $\times 20 \times 10) / 4$, onde: $\mathrm{Lc}=$ número total de leucócitos contados em $4 \mathrm{~mm}^{2} ; 4=$ factor de conversão para $1 \mathrm{~mm}^{3} ; 20=$ factor de conversão da diluição utilizada; $10=$ factor de conversão para $1 \mathrm{~mm}^{3}$ (profundidade da lâmina). Para contagem diferencial de leucócitos foi utilizada a técnica do esfregaço sanguíneo. Para coloração do esfregaço foi utilizado o kit Panótico Rápido LB Laborclin Ltda. Os diferentes elementos foram contabilizados através da utilização de um contador electrónico KACIL com teclas correspondentes a cada tipo de célula.

Macrófagos broncoalveolares: Animais anestesiados (via intra-peritoneal com solução cloralose a $0.5 \%$ e uretana a $12.5 \%$ na dose de $0.8 \mathrm{ml}$ por $100 \mathrm{~g}$ de peso do animal). $\mathrm{O}$ exudato broncoalveolar foi adquirido por injecção de soro fisiológico (SF) à temperatura ambiente, através de cânula plástica inserida na traqueia (7). Várias alíquotas de $2 \mathrm{ml}$ de $\mathrm{SF}$ foram injectadas e imediatamente aspiradas. Ao final, colectouse um volume de $20 \mathrm{ml}$ de lavado broncoalveolar por cada animal que corresponderia a cerca de $3 \times 10^{6}$ de macrófagos em cada lavado. 
Taxa de fagocitose: Foram utilizados fungos

(Saccharomyces sp.) para avaliar a taxa de fagocitose de acordo com a técnica de Malageño et al. (17). Os fungos foram lavados 2 vezes com solução PBS, contados $10^{7}$ células e em seguida misturados na suspensão de macrófagos ( $1 \times 10^{6} / \mathrm{ml}$ em meio de cultura completo, RPMI 1640) recuperados do lavado broncoalveolar. As células (macrófagos e fungos) foram distribuídas em lâminas de microscopia óptica e incubados a $37^{\circ} \mathrm{C}$, em atmosfera húmida durante 1 hora. As lâminas foram lavadas com água destilada e utilizado o kit panótico rápido para a coloração. As lâminas foram lidas ao microscópio óptico com objectiva de 100x sob imersão. A taxa de fagocitose foi obtida como percentual de macrófagos que englobaram o fungo em uma contagem total de 100 células.

\section{Análise estatística}

A estatística descritiva está expressa em média e desvio-padrão. Para comparar os valores pré e pós procedimento do stress foi utilizado o t-test Student pareado. Para comparação entre os grupos, foi utilizada a análise de variância (ANOVA). Quando a ANOVA revelou diferença significativa, utilizamos o teste de Tukey de comparação múltipla. A significância foi mantida em $5 \%$ em todos os casos.

\section{RESULTADOS}

O peso corporal dos animais foi avaliado semanalmente. Os animais E apresentaram um menor ganho de peso corporal $(\mathrm{p}<0.05)$ a partir da $5^{\mathrm{a}}$ semana quando comparados aos animais NE (Figura 1).

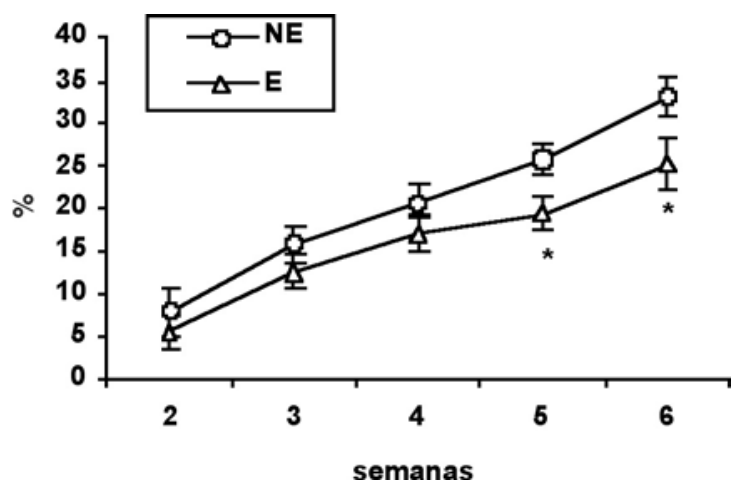

Figura 1. Valores médios $\pm D P$ do ganho de peso corporal dos animais $N \varepsilon$ e $\varepsilon$. Teste t-student para comparação entre os grupos. ${ }^{*} p<0.05$.
Com relação à percentagem de hematócrito, à concentração de hemoglobina e à contagem de hemácias, os grupos estudados não diferiram entre si (Tabela 1).

Tabela 1: Série vermelha do sangue dos grupos estudados (média $\pm D P$ ]

\begin{tabular}{|c|c|c|c|}
\hline \multirow[b]{2}{*}{ Grupos } & \multicolumn{3}{|c|}{ Parâmetros avaliados } \\
\hline & $\begin{array}{c}\text { Hematócrito } \\
{[\%]}\end{array}$ & $\begin{array}{l}\text { Hemoglobina } \\
(\mathrm{mg} / \mathrm{dl})\end{array}$ & $\begin{array}{c}\text { Hemácias } \\
\text { [nº de células } x \\
10^{5} \text { ] }\end{array}$ \\
\hline $\operatorname{NE}[n=15]$ & $42,4 \pm 2.3$ & $14,3 \pm 1.0$ & $7,4 \pm 1.5$ \\
\hline$N E+S(n=16)$ & $41,2 \pm 2.4$ & $14,1 \pm 1.6$ & $7,3 \pm 1.1$ \\
\hline$E(n=15)$ & $42.6 \pm 2.9$ & $14.4 \pm 1.1$ & $7,6 \pm 2.6$ \\
\hline$E+S(n=15)$ & $41.1 \pm 2.0$ & $13.9 \pm 1.5$ & $7,3 \pm 1.8$ \\
\hline
\end{tabular}

$\mathrm{Na}$ contagem total de leucócitos do sangue periféri$\mathrm{co}$, o grupo $\mathrm{NE}+\mathrm{S}$ apresentou uma diminuição comparativamente aos valores pré stress de contenção (pré $=12,6 \pm 0,7$ e pós $=7,3 \pm 0,4$ ) (Figura 2 ). Da mesma forma, esta diminuição foi verificada quando todos os grupos estudados foram comparados no segundo momento da colecta de sangue $(\mathrm{DN}=13.1$ $\pm 0.6 ; \mathrm{NE}=11.9 \pm 1.2 ; \mathrm{NE}+\mathrm{S}=7.3 \pm 0.4 ; \mathrm{E}=11.2$ $\pm 0.9 ; \mathrm{E}+\mathrm{S}=11.9 \pm 1.0)$. Vale salientar que os animais $\mathrm{E}+\mathrm{S}$ não apresentaram diminuição na contagem total de leucócitos quando os valores pré e pós stress de contenção foram comparados (pré = 12.9 \pm 1.1 e pós $=11.9 \pm 1.0$ ) (Figura 2 ). Os valores dos animais DN não diferiram do grupo NE.

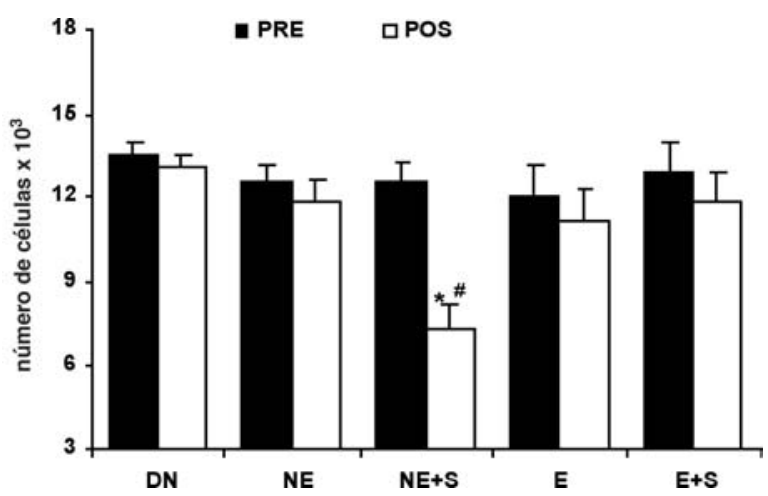

Figura 2: Valores médios $\pm D P$ da contagem total de leucócitos dos grupos estudados. Teste t-student pareado para comparação dos valores médios pré e pós intervenção. Teste ANOVA, seguido do teste de TUKEY para comparação entre os grupos pós intervenção. ${ }^{*} p<0.05 N \varepsilon+S$ (pré) vs $N \varepsilon+S$ (pós) e \#p<0.05 $N \varepsilon+S$ vs $N \varepsilon$ na comparação entre os grupos. $D N=$ dado normativo $(n=5)$. 
Relativamente à contagem diferencial de leucócitos, quando comparado ao grupo NE o grupo $\mathrm{NE}+\mathrm{S}$ apresentou uma diminuição no número de linfócitos $(\mathrm{NE}=76.7 \pm 1.2$ e $\mathrm{NE}+\mathrm{S}=68.8 \pm 1.4)$ e um aumento no número de neutrófilos $(\mathrm{NE}=19.7 \pm 2.1$ e $\mathrm{NE}+\mathrm{S}=27.7 \pm 1.3$ ). Este perfil leucocitário não foi verificado no grupo $\mathrm{E}+\mathrm{S}$ (neutrófilos $=21.6 \pm$ 1.8 e linfócitos $=74.4 \pm 2.2$ ) quando comparado ao NE (Figura 3). Nas demais células analisadas, monócitos, eosinófilos e basófilos, não houve diferença entre os grupos (dados não apresentados).

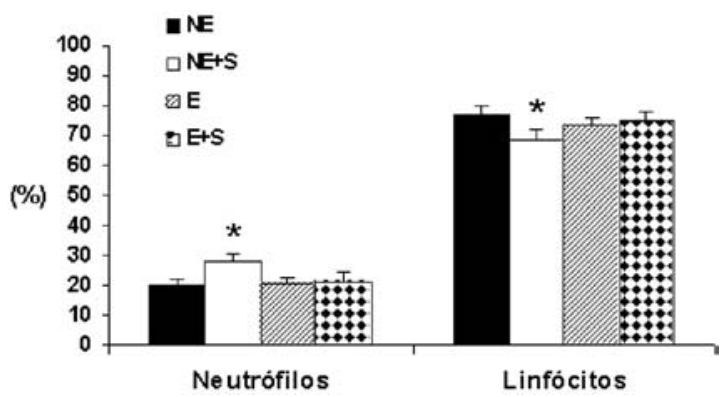

Figura 3: Valores médios $\pm D P$ da contagem diferencial de leucócitos dos grupos estudados. Teste ANOVA, seguido do teste de TUKEY. ${ }^{*} p<0.05 N \varepsilon+S$ vs NE.

Os animais $\mathrm{NE}+\mathrm{S}$ apresentaram uma diminuição na taxa de fagocitose quando comparado aos demais grupos estudados. $\mathrm{O}$ grupo $\mathrm{E}$ apresentou um aumento e o grupo $\mathrm{E}+\mathrm{S}$ não demonstrou alteração com relação ao grupo $\mathrm{NE}(\mathrm{NE}=26.7 \pm 2.1 ; \mathrm{NE}+\mathrm{S}=$ $21.0 \pm 2.3 ; \mathrm{E}=32.1 \pm 2.8 ; \mathrm{E}+\mathrm{S}=25.9 \pm 3.0$ ) [Figura 4].

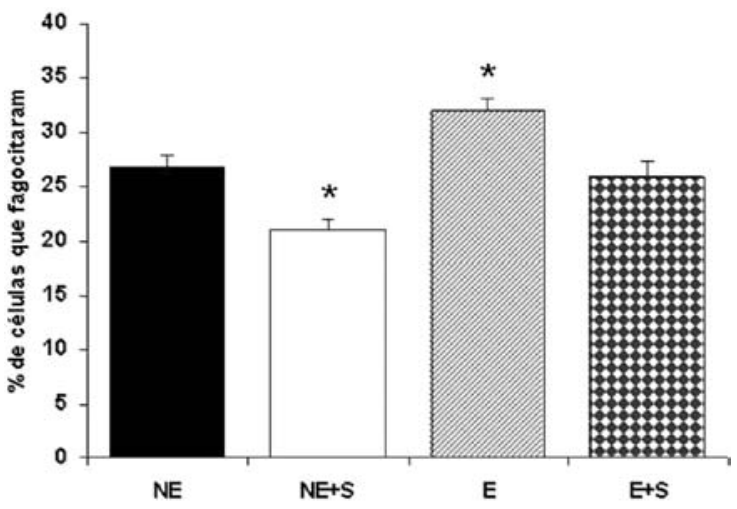

Figura 4: Valores expressos em média $\pm D P$ da percentagem de células que fago citaram o fungo. Teste ANOVA, seguido do teste de TUKEY. ${ }^{*} p<0,05 N \varepsilon+S$ vs $N \varepsilon$.

\section{DISCUSSÃO}

O exercício físico está associado à modulação da dinâmica e de algumas funções de células imunes $(12,13)$. A intensidade, o tipo e a duração do esforço parecem ser factores determinantes no estudo destas respostas (28). O presente estudo demonstrou que os animais submetidos à natação durante 6 semanas previamente a uma situação de stress apresentaram alteração no perfil leucocitário comparativamente aos animais sedentários e estressados. Os mecanismos relativos ao efeito do treinamento não estão esclarecidos, mas podem estar associados ao aumento da tolerância de células imunes quando expostas a cargas agudas de EF (30). Diferentes células podem adaptar-se na dependência do tipo celular, intensidade do stress e de outros factores (29).

Várias adaptações fisiológicas ocorrem a seguir a um período de EF crónico. Uma alteração característica é o aumento da taxa metabólica ou do dispêndio energético a seguir ao período de exercício (14). O peso corporal ou o ganho de peso corporal a seguir ao treinamento têm sido utilizados para avaliação do aumento da taxa metabólica (3). No presente estudo, os animais exercitados apresentaram um menor ganho de peso corporal a partir da quinta semana de natação. Por outro lado, os animais não-exercitados apresentaram em média $22 \%$ a $30 \%$ de aumento. Estes resultados concordam com estudos previamente realizados com animais expostos ao treinamento de natação $(12,13,14,20)$. A mobilização de ácidos graxos dos adipócitos e a utilização destes como fonte de energia no músculo esquelético parecem estar subjacentes às adaptações fisiológicas inerentes ao exercício físico regular $(14,21)$.

Para obtermos o efeito crónico do EF sobre as componentes do SI, as avaliações foram realizadas 24 horas a seguir à última sessão de exercício. Neste sentido, evitámos o efeito agudo do EF sobre alguns parâmetros imunológicos. Segundo Hoffman-Goetz (12) muitas das alterações ocorridas no SI são transitórias e retornam aos valores basais dentro de 24 horas a seguir ao esforço, com excepção dos níveis plasmáticos de algumas citocinas.

Com relação à contagem de hemácias, a concentração de hemoglobina e a percentagem de hematócrito, os diversos grupos não apresentaram alterações. Este resultado vai de encontro aos estudos que rela- 
tam um aumento no hematócrito e na hemoglobina em animais submetidos ao stress físico agudo $(15,26)$. De facto, os animais, mas não o homem, são capazes de estocar grande quantidade de eritrócitos no baço e expeli-los na circulação quando o sistema transportador de oxigénio está sob stress (15). Este mecanismo é facilitado via sistema nervoso simpático (SNS) que resulta numa contracção da musculatura lisa do baço e uma subsequente diminuição do seu volume (15). O facto de termos utilizado um protocolo diferente de stress (contenção) nos animais pode justificar os diversos resultados encontrados.

No presente estudo, não houve alteração da concentração de hemoglobina em resposta ao EF crónico. Vários autores têm demonstrado que uma das respostas adaptativas ao EF crónico com relação ao fornecimento de oxigénio para o tecido activo parece ser o aumento da concentração de 2,3-difosfoglicerato nas hemácias $(15,26)$. Este composto une-se a subunidades da molécula de hemoglobina, reduzindo sua afinidade com o oxigénio (26). Isso resulta em maior disponibilidade de oxigénio para os tecidos mesmo a uma $\mathrm{PO}_{2}$ reduzida.

Devido à grande amplitude dos valores normativos da contagem total de leucócitos do sangue observada em ratos (8,0 - $15 \times 10^{3}$ células), decidimos avaliar no mesmo animal os valores pré e pós os procedimentos experimentais. Da mesma forma, a manipulação diária dos animais não-exercitados poderia oferecer algum tipo de stress e interferir nos resultados.

Assim, comparamos os valores do grupo NE com animais que não sofreram nenhum tipo de intervenção (DN). Não observámos diferença entre o grupo controle (NE) e os dados normativos do experimento. Nossos resultados demonstraram que o stress resultou numa diminuição de leucócitos totais comparativamente tanto aos valores pré-tratamento como aos demais grupos estudados. Esta diminuição pode ter associação com a libertação das hormonas do stress e resultar de uma redistribuição de células da circulação para os tecidos $(3,4,12)$. De facto, as células do SI parecem possuir receptores para as várias hormonas do stress tais como os glucocorticóides e as catecolaminas (16).

A expressão de $\beta$-receptores nas diferentes células imunes fornece a base molecular para acção das cate- colaminas (16). Contudo, a densidade de receptores adrenérgicos e a eficiência do sistema de transdução AMPc diferem nos vários tipos de células imunocompetentes $(5,16)$. Os neutrófilos e os linfócitos parecem apresentar maior número de receptores comparativamente a outras células do SI (13). Em resposta ao stress agudo, verificámos uma diminuição na contagem de linfócitos e um aumento na contagem de neutrófilos. Neste sentido, é provável que a resposta imediata destas células aos efeitos do stress decorra do efeito modulador das catecolaminas. A significância clínica destas alterações ainda não está esclarecida, mas acredita-se que esteja relacionada aos estados de imunossupressão induzidos pelo stress.

Outro mecanismo que pode estar associado à diminuição dos linfócitos na circulação em resposta ao stress é a estimulação da apoptose destas células pelo aumento da concentração de glucocorticóides $(1,8,22)$. Apoptose ou "morte celular programada" ocorre de forma organizada, disparada em períodos determinados, que não gera reacção inflamatória e parece desempenhar um importante papel no organismo (1). Entretanto, as alterações na homeostase orgânica podem aumentar o número de células apoptóticas de forma a comprometer o mecanismo de defesa (1).

Os animais exercitados e submetidos ao stress não apresentaram alterações na contagem total e diferencial de leucócitos. De facto, o EF crónico está associado a adaptações fisiológicas e hormonais (3). Recentemente, tem sido demonstrado que o stress crónico pode estar associado às alterações imunorreguladoras dos glucocorticóides $(10,14,24)$. Em particular, tem sido visto que o stress crónico está associado ao aumento de glucocorticóides e reduzida sensibilidade de linfócitos do sangue periférico para estas hormonas in vitro (8). Estes dados sugerem que o stress pode alterar a resposta de linfócitos à sinalização dos esteróides.

No presente estudo, verificámos uma diminuição da taxa de fagocitose de macrófagos. Este resultado corrobora estudo prévio (18). Os macrófagos são importantes células efectoras, altamente reguladas por outras células (linfócitos T e B) e por mediadores químicos produzidos pelo SNS e pelo eixo hipotálamo-pituitária-adrenal (HPA) [30]. 
Particularmente, a função de fagocitar os microorganismos e as células danificadas parece ser sensível à acção dos glucocorticóides (2). Moinard et al. (18) verificaram uma diminuição da actividade fagocítica de macrófagos de ratos estressados. Estes autores atribuíram esta diminuição à presença de níveis elevados de glucocorticóides. Por outro lado, de acordo com os nossos dados e de outros estudos, o EF crónico induziu um aumento da actividade fagocítica destas células $(29,30)$. Foi interessante observar que os animais exercitados e estressados não apresentaram diminuição na taxa de fagocitose. Estes resultados sugerem que a natação durante um período de 6 semanas resulta em melhora da resposta de macrófagos alveolares ao stress com relação à taxa de fagocitose. Os mecanismos subjacentes a estas respostas ainda permanecem desconhecidos, mas podem estar associados a factores neuroendócrinos $(3,29)$.

\title{
CONCLUSÃO
}

Em conclusão, o stress agudo de contenção induz leucopenia, linfopenia, neutrofilia e diminuição na taxa de fagocitose de macrófagos. O exercício físico crónico parece reverter este quadro. A significância clínica destas alterações, assim como os mecanismos de acção hormonal ou de outros mediadores merecem maiores estudos.

\author{
Agradecimento \\ Os autores gostariam de agradecer o apoio financei- \\ ro da Fundação de Apoio à Ciência do Estado de \\ Pernambuco (FACEPE) e do Conselho Nacional de \\ Pesquisa (CNPq).
}

\section{CORRESPONDÊNCIA}

\section{Carol Góis Leandro}

Departamento de Nutrição

Laboratório de Fisiologia da Nutrição - CCS

Universidade Federal de Pernambuco,

Cidade Universitária,

50670-901, Recife, PE-Brasil.

carolgois6@hotmail.com 


\section{REFERÊNCIAS BIBLIOGRÁFICAS}

1. Avula C, Muthukumar A, Zaman K, McCarter R, Fernandes G (2001). Inhibitory effects of voluntary Wheel exercise on apoptosis in splanic lymphocyte subsets of C57BL/6 mice. J Appl Physiol. 91: 2546-2552.

2. Bacurau R, Belmonte M, Seelaender C, Costa Rosa L (2000) Effect of a moderate intensity exercise training protocol on the metabolism of macrophages and lymphocytes of tumourbearing rats. Cell Biochem Funct. 18: 249-258.

3. Brenner I, Shek PN, Zamecnik J, Shephard RJ (1998). Stress Hormones and the immunological responses to heat and exercise. Int J Sports Med 10: 130-143.

4. Brenner IK, Natale VM, Vasiliou P, Moldoveanu AI, Shek PN, Shephard RJ (1999). Impact of three different types of exercise on components of the inflammatory response. Eur J Appl Physiol Occup Physiol: 80(5):452-60.

5. Ceddia M, Price E, Kohlmeier C, Evans J, Lu Q, McAuley E, Woods J (1998). Differential leukocytosis and Lymphocyte mitogenic response to acute maximal exercise on the Young and old. Med Sci Sports Exerc. 31 (6):829-836

6. De Castro CB, Manhães-de-Castro R, Queirós A, Costa JA., Brandt CT (1999). Stress: Interações neuroendócrinas e imunológicas. Anais Faculd de Med CCS - UFPE. 44 (2): 132-137.

7. De Castro CB., Manhães-de-Castro R, Medeiros AF, Queirós A, Ferreira WT, Lima Filho JL. (2000) Effect of stress on the production of $\mathrm{O}_{2}{ }^{-}$in alveolar macrophages. $J$ Neuroimmunol. 108 (1) 68-72.

8. Fry RW, Morton AR, Crawford GP, Keast D (1992). Cell numbers and in vitro responses of leukocytes and lymphocyte subpopulations following maximal exercise and interval training sessions of different intensities. Eur J Appl Physiol 64:218-227.

9. Gillis S, Crabtree G, Smith K (1979). Glucocorticoid-induced inhibition of $\mathrm{T}$ cell growth factor production. The Journal of Immunology. 123 (4): 1632-1637.

10. Green K, Rowbotton D, Mackinnon L (2002). Exercise and T-lymphocyte function: a comparison of proliferation in PBMC and NK cell-depleted PBMC culture. J Appl Physiol. 92: 2390-2395.

11. Hainline A Jr. (1958). Standard methods of clinical chemistry. New York: Academic Press.

12. Hoffman-Goetz L, Simpson JR, Cipp N, Arumugam Y, and Houston ME. (1990). Lymphocyte subset responses to repeated submaximal exercise in men. J Appl Physiol 68: 1069-1074.

13. Kendall A, Hoffman-Goetz L., Houston M., MacNeil B, Arumugam Y. (1990). Exercise and blood lymphocyte subset responses: intensity, duration, and subject fitness effects. J. Appl. Physiol 69: 251-260.

14. Kim H, Shin S, Kim S, Lim B, Kim Y, Chumg J, Kim H, Kim C (2003). Modulation of immune responses by treadmill exercises in Sprague-Dawley rats. J Sports Med Phys Fitness. 43: 99-104.

15. Kuwuahira I, Kamiya U, Iwamoto T (1999). Splenic contraction-induced reversible increase in hemoglobin concentration in intermittent hypoxia. J Appl Physiol. 37: 399-420.

16. Leandro C, Nascimento E, Manhães-de-Castro R, Duarte J, de-Castro C (2002). Exercício Físico e Sistema imunológico: mecanismos e integrações. Rev Port Ciências do Desp. 2 (5): 80-90.
17. Malagueño E, Albuquerque C, de Castro CMMB, Gadelha M, Irmão JI, Santana JV (1998). Effect of Biomphalaria straminea Plasma in the Phagocytosis of Biomphalaria glabrata Hemolymph Cells. Mem Inst Oswaldo Cruz. 93(1): 301-302.

18. Moinard C, Caldefie F, Walrand S, Felgines C, Vasson M e Cynober L (2000). Involvement of glutamine, arginine, and polyamines in the action of ornithin _-ketoglutarate on macrophages functions in stressed rats. J of Leukocyte Biology. 67:834-839.

19. Moldeveanu AI, Shephard RJ, Shek PN (2001). The cytokyne response to physical activity and training. Sports Med. 31 (2): 115-144.

20. Mooren F, Bloming D, Lechtermann A, Lerch M, Volker K (2002). Lymphocyte apoptosis after exhaustive and moderate exercise. J Appl Physiol. 93: 147-153.

21. Moraska A, Deak T, Spencer R, Roth D, Fleshner M (2000). Treadmill running produces both positive and negative physiological adaptations in Sprague-Dawley rats. Am J Physiol Regulatory Integrative Comp Physiol. 279: R1321-R1329.

22. Nieman DC. (2000). Is infection risk linked to exercise workload? Med Sci Sports Exerc 32(7):S406-411.

23. Pyne DB, Smith JA, Baker MS, Telford RD, Weidemann MJ.(2000) Neutrophil oxidative activity is differentially affected by exercise intensity and type. J Sci Med Sport 3(1):44-54

24. Shastry S, Toft D, Joyner (2002). HSP70 and HSP90 expression in leucocytes after exercise in moderately trained humans. Acta Phisiol Scand. 175: 139-146.

25. Stefanski V, Engler H (1998). Effects of acute and chronic social stress on blood cellular immunity in rats. Physiology and Behavior 64 (5): 733-741.

26. Stewart I e McKenzie D (2002). The human spleen during physiological stress. Sports Med. 32 (6): 361-369.

27. Stibbe W, Weise M, Seidel D (1985). Automated platelet count in thrombocytopenic patients-a comparison of methods. J Clin Chem Clin Biochem. 23(7):399-404.

28. Tvede N, Kappel M, Halkjaer-Kristensen J, Galbo H, and Pedersen BK. (1993). The effect of light, moderate and severe bicycle exercise on lymphocyte subsets, natural and lymphokine activated killer cells, lymphocyte proliferative response and interleukina-2 production. Int J Sports Med 14: 275-282.

29. Woods J, Lu Q, Ceddia MA, Lowder T (2000). Special feature for the Olympics: effects of exercise on the immune system: exercise-induced modulation of macrophage function. Int J Sports Med 21 S1:S24-30.

30. Woods JA, Davis JM, Smith JA, Nieman DC (1999). Exercise and cellular innate immune function. Med Sci Sports Exerc. 31(1): 57-76. 